\title{
Value Justification of Safe Distances from Trunk-Lines by the Methods of Quantitative Risk Assessment
}

\author{
Anton Vengerov ${ }^{1, *}$, Vitaliy Stroyenko ${ }^{2}$, Aleksey Gladenko ${ }^{3}$, and Vladimir Karagusov ${ }^{3}$ \\ ${ }^{1}$ Industrial University of Tyumen, 625001 Volodarskogo str. 38, Tyumen, Russia \\ ${ }^{2}$ SIBUR, 016695 Krzhizhanovskogo st. 16/1, Moscow, Russia \\ ${ }^{3}$ Omsk State Technical University, 639548 Mira st. 11, Omsk, Russia
}

\begin{abstract}
The paper discusses the methods of substantiation of safe distances from the pipelines to transport WFLH (Wide Fraction of Light Hydrocarbons) by the methods of quantitative risk assessment. Recommendations are given to maintain the level of probability of occurrence of an accident or failure, as well as their consequences within the given limits of the regulations. Viewed technique was tested on a specific example of the pipeline.
\end{abstract}

\section{Introduction}

Trunk-line system (TS), which is unique in extent, performance and security, is being operated and developed in Russia. The data on accidents and injuries indicate that the accident with loss of people's life in the TS is quite a rare event. However, in the modern urban environment the risk of major industrial accidents involving loss of life increases due to approaching of TS to human locality, production facilities and transport infrastructure. The greatest risk is associated with the operation of the TS, pumping volatile liquid hydrocarbons (liquefied petroleum gases, unstable condensate, broad fraction of light hydrocarbons, with the accidental release of which clouds of the fuel-air mixtures can form that can drift under adverse conditions in the distance of several hundred meters while maintaining a fire capacity $[1,2]$.

To date, substantial experience in modeling of accidental releases, the calculation of the consequences of accidents at industrial sites and the use of risk analysis methodologies for the assessment of hazards of possible accidents is gained in the works of V.A. Akimova, M.V. Beschastnova, O.M. Ivantsova, A.M. Kozlitina, M.V. Lisanova, S.V. Ovcharov, G.E. Odisharia, A.S. Pecherkina, V.S. Safonov, V.I. Sidorova, S.I. Sumy, S.A. Timasheva, A.A. Shvyryaeva, Y.N. Shebeko, T. Kletz, F. Lees, K. Muhlbauer and other Russian and foreign researchers. Among the ways to ensure the safety of people from accidents the most famous and reliable one is removal of objects from the source of danger at a sufficient distance ("distance protection"). Under the threat of major industrial accidents with the group death of people the issue of establishing safe distances arises particularly acute. After a wellknown example of the Ufa catastrophe of 1989 some changes were made in the SBRR (a

*Corresponding author: vengerov_tsogu@mail.ru 
Set of Basic Requirements and Regulations) 2.05.06-85 * "Pipelines", which established the extremely pessimistic minimum distance from the LPG product lines. Actually the changes slowed down the design and construction of new objects for decades [3-5].

To establish minimum safety distances to adjacent structures and infrastructure is one of the most important problems of industrial and fire safety in the design and operation of the TS of LPG in connection with the national development plan and gas petrochemical Russia until 2030. The solution to this problem should be based on an analysis of the current state of accidents [6].

\section{Research object (Model, Process, Device, Synthesis, Experimental part, etc.)}

The wide fraction of light hydrocarbons (WFLH) is a product of processing of associated petroleum gas and gas condensate. It is a mixture of liquefied petroleum gas and heavier hydrocarbons (C2-C6 and above). In general, a typical WFLH composition is the following one: ethane from 2 to 5\%; LPG C4-C5 fractions 40-85\%; C6 hexane fraction from 15 to $30 \%$ and pentane fraction accounts for the remainder. WFLH is not a commercial product, so it is in any case transported to the processing and gas chemical plants for further processing. Russia has huge production facilities for processing of wide fraction of hydrocarbons, but they are located remotely from the fields (Table 1).

Table 1. The main production facilities of WFLH

\begin{tabular}{|c|c|c|c|c|c|}
\hline Company & $\begin{array}{c}\text { Date of } \\
\text { foundation }\end{array}$ & Owned by & Raw material & $\begin{array}{c}\text { Productivit } \\
\text { y on raw } \\
\text { materials }\end{array}$ & $\begin{array}{c}\text { Productivity } \\
\text { on WFLH }\end{array}$ \\
\hline Surgut PCS [2]. & 1984 & GAZPROM & $\begin{array}{c}\text { De-ethanized } \\
\text { gas condensate }\end{array}$ & $\begin{array}{c}12 \mathrm{mln} \text {. } \\
\text { tons per } \\
\text { year }\end{array}$ & $\begin{array}{c}\text { up to } 3.3 \\
\text { mln. tons per } \\
\text { year }\end{array}$ \\
\hline $\begin{array}{c}\text { Purovsky PCS } \\
\text { [3] }\end{array}$ & 2004 & NOVATEK & $\begin{array}{c}\text { De-ethanized } \\
\text { gas condensate }\end{array}$ & $\begin{array}{c}11 \mathrm{mln} . \\
\text { tons per } \\
\text { year }\end{array}$ & $\begin{array}{c}3.3 \text { mln. tons } \\
\text { per year }\end{array}$ \\
\hline $\begin{array}{c}\text { Nizhnevartovsk } \\
\text { GPP [4] }\end{array}$ & 1974 & SIBUR & $\begin{array}{c}\text { Associated } \\
\text { petroleum gas }\end{array}$ & $\begin{array}{c}16.2 \text { billion } \\
\text { m3 per } \\
\text { year }\end{array}$ & $\begin{array}{c}\text { up to } 1,8 \\
\text { mln. tons per } \\
\text { year }\end{array}$ \\
\hline $\begin{array}{c}\text { Belozerny GPP } \\
\text { [4] }\end{array}$ & 1978 & SIBUR & Associated \\
petroleum gas & $\begin{array}{c}4.2 \text { bln. m3 } 3 \\
\text { per year }\end{array}$ & $\begin{array}{c}\text { up to } 1.26 \\
\text { mln. tons per } \\
\text { year }\end{array}$ \\
\hline $\begin{array}{c}\text { South Balyksky } \\
\text { GPP [4] }\end{array}$ & 1974 & SIBUR & $\begin{array}{c}\text { Associated } \\
\text { petroleum gas }\end{array}$ & $\begin{array}{c}2.8 \text { bln. m3 } \\
\text { per year }\end{array}$ & $\begin{array}{c}\text { up to } 0.9 \\
\text { mln. tons per } \\
\text { year }\end{array}$ \\
\hline $\begin{array}{c}\text { Vyngapurovsky } \\
\text { GPP [4] }\end{array}$ & 2011 & SIBUR & $\begin{array}{c}\text { Associated } \\
\text { petroleum gas }\end{array}$ & $\begin{array}{c}2.4 \text { bln. m3 } \\
\text { per year }\end{array}$ & $\begin{array}{c}\text { up to } 0.64 \\
\text { mln. tons per } \\
\text { year }\end{array}$ \\
\hline $\begin{array}{c}\text { Gubkinsky GPP } \\
{[4]}\end{array}$ & 1988 & SIBUR & $\begin{array}{c}\text { Associated } \\
\text { petroleum gas }\end{array}$ & $\begin{array}{c}2.1 \text { bln. m3 } \\
\text { per year }\end{array}$ & $\begin{array}{c}\text { up to } 0.63 \\
\text { mln. tons per } \\
\text { year }\end{array}$ \\
\hline
\end{tabular}

\section{Causes and consequences of accidents on pipelines for WFLH.}

According to regulatory documents [6], an accident on the pipeline is defined as the destruction of the pipeline, an uncontrolled explosion and (or) release of liquid or gaseous 
substances transported by pipeline. It is accompanied by one or more of the following events:

- inflammation of the transported substances, vapor or gas mixture;

- pollution of the water body in excess of the maximum permissible concentrations of harmful substances;

- leakage of transported liquid substance in an amount of 25 tons or more tons;

Classification of accidents and failures in pipelines for WFLH differs little from the traditional one for the majority of the objects of the main transport of hydrocarbons [7]. Among these accidents can be identified:

- depressurization of the pipeline with the spill of pumped medium;

- depressurization of the pipeline with the ignition of the pumped medium;

- depressurization of the pipeline with the explosion of the pumped medium.

The potential danger of accidents on pipelines for WFLH is compounded by the fact that they are prone to instant boiling up, and their clouds can be ignited over several kilometers. There were a lot of accidents on pipelines for petroleum products and volatile hydrocarbons in the history, which led to the loss of billions of dollars and hundreds of deaths. However, most of them took place in countries with warm climate (Kenya, Nairobi, Mexico). It contributed to the rapid ignition of the pumped product when mixed with air. However, in the summer period Western Siberia is hot enough and large seasonal temperature variations contribute to the accumulation of defects in the metal pipes (Table 2).

Table 2. The causes of accidents and failures in TS

\begin{tabular}{|c|c|}
\hline Reasons of accidents & \% of total \\
\hline External corrosion & 28.9 \\
\hline including SCC (Stress Corrosion Cracking) & 22.5 \\
\hline Mechanical damage & 19.0 \\
\hline Defect of construction and installation work & 21.9 \\
\hline including defect in welding & 13.0 \\
\hline Defects of pipes & 11.4 \\
\hline Natural disasters & 9.5 \\
\hline
\end{tabular}

\section{Methods}

As with any object oil and gas pipelines for natural gas liquids are especially dangerous. For this reason, safe distances from the MT to the infrastructure must be particularly justified. As any object OF oil and gas industry pipelines for WFLH are especially dangerous. For this reason, safe distances from the ST to the infrastructure must be particularly justified.

However, at the same time there is no clear guidance on the definition of a safe distance from the pipeline for WFLH to industrial and civil objects. Recommendations of SBRR 2.05.06-85 are limited to specific values of minimum distances depending on the group WFLH, pipe diameter and type of object. The specified standards were accepted more than 30 years ago, the last update was made in 2010 , but the reason to consider their legacy lies not only in this fact $[8,9$, etc $]$.

According to the latest revision of standards, WFLH include mixtures containing 5.3\% of ethane, whereas in most cases mixtures, which contain $10-15 \%$ of ethane fraction, are transported through pipelines. The next discrepancy is the result of the first. A large proportion of ethane in the mixture causes a phase of high pressure of its saturated vapor, which in turn creates a need to reduce the inter-station distances in order to prevent the 
formation of two-phase flow. It is clear that it is possible to achieve it by increasing the number of pumping stations. Thus, there is another factor that affects the safety and the cost of pumping gas liquids.

In addition, with vigorous vaporization arising due to depressurization of the pipeline, there is a significant drop in temperature of the pumped liquid, which entails cooling of the pipe wall. Numerical modeling of lowering temperature of WFLH in the place of pipeline rupture site showed that its value can reach $-45^{\circ} \mathrm{C}$, resulting in brittle fracture of the pipeline. This problem can be solved by hardening metal pipes alloying elements, but operating specifications does not provide it.

In addition to the actions listed above, SBRR 2.05.06-85 has a number of other inconsistencies in the section relating to the design and operation of pipelines for mixtures of light hydrocarbons. Judging by the aove mentioned information we can state that the reporting guidance document is obsolete and requires new approaches to the formation of rules and recommendations for pipelines that transport unstable mixture of hydrocarbons.

An accident on the main pipelines near Ufa in June 4, 1989 was the most significant one in Russia. There were two passenger trains in the area of the explosion, nearly 600 people were killed and the same number of people was injured. After this incident SBRR 2.05.06$85 *$ recommended safe distances between populated areas and pipelines were revised in the direction of a significant increase [10].

Some suggestions were made repeatedly and insistently that when designing modern pipelines for WFLH one should turn to the experience of leading foreign companies engaged in the construction and operation of the main product lines. However, analysis of foreign documents indicates that in some countries there are no statutory rules of safe location of pipeline transport facilities on the items with large concentrations of people.

It is possible to rate a safe distance from the water supply to residential or industrial facility by a number of ways.

The analysis of the experience occurred accidents and failures is the most common method. This method is partially reflected in the SBRR 2.05.06-85*. Sufficiently indicative statistics shows that the size of the affected areas in case of accidents on pipelines for natural gas liquids ranges from 100 to 350 meters away from the axis of the pipeline (thermal radiation, scattering fragments). These boundaries in the first approximation can be determined by diameter and the pressure in the pipeline. This approach does not require the use of any safety factors. However, WFLH ability to fire at a sufficiently large distance from the accident site, requires the repeated increase of these distances.

The second method is based on analyzing the consequences of the maximum hypothetical accident involves the total destruction of the pipeline with the pipeline considering the specific characteristics (geometric parameters, installation conditions, physical properties of the pumped medium, etc.). In this case, the safety factors are implicitly laid in various conventions .

The third method is based on a quantitative assessment of the risk of an accident. The advantage of this method is that one of its principles is the very definition of the probability of an accident or failure, including the maximum. The method allows to evaluate all the accident scenarios in a specific section of the pipeline, the leakage through a defect of any size, as well as all the options on the basis of the outcome of an event tree that allows the fate of the maximum number of factors of impact on the pipeline. The main purpose of risk assessment is to present on the basis of objective evidence the information needed to make informed decisions about risk treatment methods.

Among many methods recommended for the use of quantitative risk assessment the analysis of the causes and consequences [8] is the most appropriate.

The method of analysis of the causes and consequences was originally developed as testing tool system reliability, critical for security, which was used for a more complete understanding of the failures of the system. As well as fault tree analysis method, this 
method is used to display the failure logic leading to critical events, however, in addition to the functionality of the fault tree, this method allows to analyze the sequence of failures. The method also allows you to take into account the time lag in the analysis of the consequences it is not possible when using the event tree method [9].

The method is used to analyze the different options of the system after the occurrence of a critical event, depending on the behavior of its subsystems (for example, alarm systems). If such options may be described quantitatively, they can be estimated probabilities of possible consequences of critical events.

\section{Results and Discussion}

As an example of this study we present the results of the risk assessment of accidents on the main reconstructed pipelines of WFLH with diameter of DN $=500 \mathrm{~mm}$ [2]. On the route of the product pipeline, there are numerous (over 50 seats) approach to human settlements, production facilities, railways and highways, including deviations from previously existing p. 3.16 of SBRR 2.05.06-85*.

Calculating the weight of leaks in emergency depressurization product pipeline [10-15] (the accident in question with four possible variants of depressurization of the pipeline, "fistula", small, medium cracks and guillotine break) and assessing areas the size of the damaging factors, was built potential risk field, its fragment is shown in Figure 1.

The calculations have shown that the potential level of risk fatalities 10-6 year-1 is achieved at a distance of 50-100 $\mathrm{m}$ from the pipeline and only on certain sections of the route; Level 10-7 year-1 - 250-350 m; 10-8 year-1 - 500-700 m.

The effectiveness of technical solutions to ensure the safety of the analyzed pipeline (frequency partition sections with stop valves, the use of modern systems of leak detection, device of protective shafts, relining and stress testing of pipes in the places od dangerous approach, and others.) can also be confirmed by quantitative risk assessment.

For example, the distribution of the homogenized mass leak of WFLH product pipeline around the track before and after the installation of additional valves is shown in Figure1.

The figure shows that the installation of additional valves leads to a significant reduction in leakage volume in some parts of 2-2.5 times.

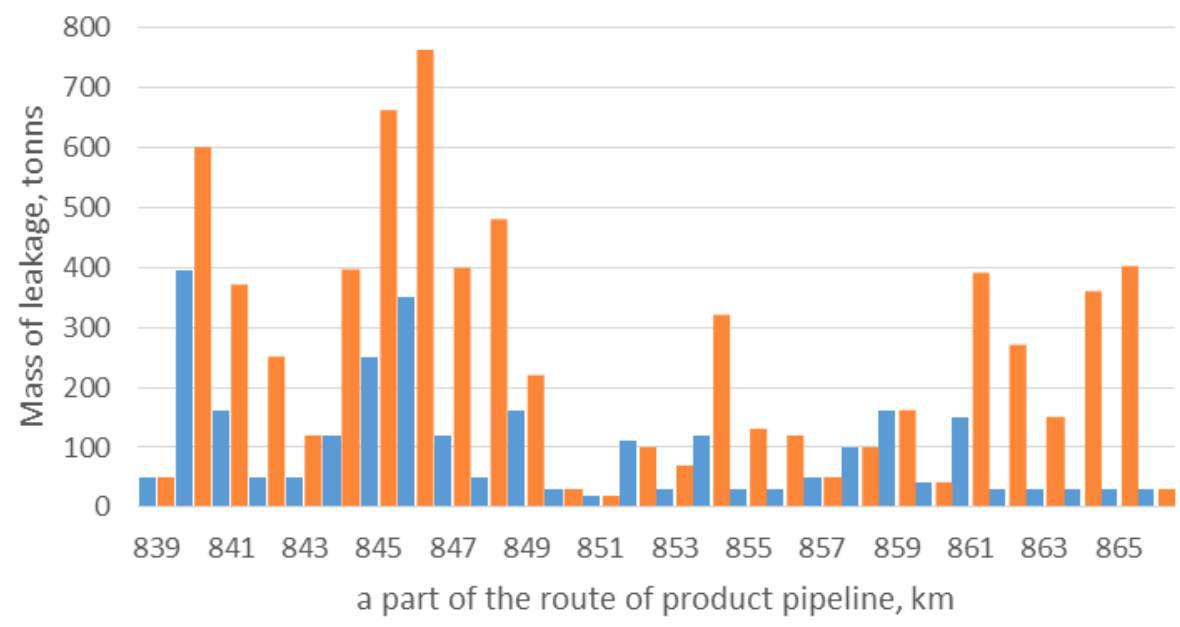

$\square 1 \square 2$

Fig. 1. Distribution of averaged scenarios of mass WFLH product pipeline leak on the highway in the area $839-867 \mathrm{~km}, 1$ and 2 - respectively, before and after the installation of additional valves. 


\section{Conclusion}

The calculations showed that the expected environmental damage caused by oil entering the water bodies, calculated as described in [8], corresponds to the "average" level of risk that may be accepted as admissible on the hard security control condition according to the standard approaches to setting criteria for acceptable risk (for example, the area called according to [16-18] "strict control zone", for which an evaluation of the appropriateness of risk mitigation measures).

In order to reduce risk to the lowest necessary to provide compensatory measures that do not allow the oil to reach the water bodies, i.e. construction of engineering structures and the use of protective covers $[19,20]$.

As a result of the quantitative risk analysis of the considered the main oil pipeline there were calculated people impact area under various scenarios of oil spills, dispersion and ignition of oil vapor. We analyzed the impact of different design decisions mentioned in [21-23] on risk indicators, including an increase in wall thickness, spacer "pipe in pipe", the construction of dams and other events.

Thus, as a result of the quantitative risk analysis methodology developed and tested to justify a safe distance from the main pipelines to settlements, industrial and agricultural facilities, taking into account the possible design solutions.

\section{References}

1. Federal Law Technical Regulations on the safety of buildings and structures from 30.12.2009 N 384-FZ, (2009)

2. S. Sumy, A. Pchelnikov, E. Savin, Occupational safety in the industry, 2, 48-52 (2007)

3. I. Mazur, O. Ivantsov, Security of piping systems (Eslim Publishing, Moscow, 2004)

4. M. Lisanov, S. Sumy, A. Savina, E. Savin, Occupational safety in the industry, 3, 5159 (2010)

5. Methodological guide for risk assessment of accidents on the main oil pipelines, Ser. 27, V. 1 (Industrial safety", Moscow, 2005)

6. Declaration of fire safety and fire risk assessment: Coll. Doc. Ser. 19. V. 2. Parts 1-4 (ZAO STC, Moscow, 2009)

7. A. Agapov, I. Lazukin, A. Maruhlenko, Occupational safety in the industry, 1, 46-52 (2010)

8. The methodology of calculation of the damages caused to water bodies due to violations of water legislation (2009)

9. Federal Law of July 22, 2008. № 123-FZ "Technical Regulations on fire safety requirements" Meeting of the legislation of the Russian Federation (2008)

10. RD 03-418-01. "Guidelines for the risk analysis of hazardous production facilities" approved (Gosgortechnadzor of Russia, 2001).

11. SP 11-113-2002

12. V. Kurushina, Yu. Zemenkov, WIT Transactions on Ecology and the Environment, 190(2), 881-888 (2014)

13. R. Levitin, Yu. Zemenkov, Neftyanoe khozyaystvo - Oil Industry, 1, 110-114 (2016)

14. E. Kurushina, V. Kurushina, Life Science Journal, 11(11), 517-521 (2014)

15. Yu. Zemenkov, V. Shalay, M. Zemenkova, Procedia Engineering, 113, 254-258 (2015)

16. Yu. Zemenkov, V. Shalay, M. Zemenkova, Procedia Engineering, 113, 312-315 (2015)

17. V. Antipyev, Yu. Zemenkov, N. Kudryavtseva, A method of calculation of losses of oil at accidents on the main oil pipelines (UMN Z and SZS, Tyumen, 1985)

18. E. Kurushina, V. Kurushina, Life Science Journal, 11(11), 517-521 (2014)

19. R. Mamadaliev, V. Kuskov, Yu. Zemenkov, A. Popova, Applied Mechanics and Materials, 770, 19-22 (2015) 
20. A. Brand, S. Vershinina, A. Vengerov, N. Mostovaya, IOP Conf. Ser.: Mater. Sci. Eng., 93, 120-125 (2015)

21. E. Kabes, K. Voronin, A. Brand, Sibresurs, (2014) 37

22. I. Kiryanov, S. Toropov, V. Toropov, Neftyanoe Khozyaystvo - Oil Industry, 8, 48 (2015)

23. A. Vengerov, A. Brand, Proceedings of the International Scientific and Technical Conference, TSOGU, Tyumen, 36-40 (2015) 